\title{
Perceptions of Teachers on Wellness of Learners Living with Physical Disabilities in Upper Primary Schools in the Hhohho Region of Eswatini
}

\author{
Lomhlangano G. Mabuza ${ }^{1}$ Racheal Mafumbate ${ }^{2 *}$ \\ 1.Hermann Gmeiner Primary School \\ 2.University of Eswatini, Department of Educational Foundations and Management, Faculty of Education
}

\begin{abstract}
The purpose of the study was to explore perceptions of teachers regarding the wellness of learners living with physical disabilities in upper primary schools in the Hhohho region of Eswatini. This study used the Wellness Theory by Hettler (1980) as its theoretical framework. The study was qualitative in its approach and it used a descriptive case study design. Through a purposive sampling, a total of 25 participants were selected, and these included 20 learners living with physical disabilities, two administrators, and three teachers. Both semistructured interview guide and focus group discussions were used for data collection. Data from findings was thematically analyzed by scrutinizing it from commonalities. The findings revealed that the teachers at the school did not have adequate training to enable them to fully assist these learners and there was lack of social wellness among the learners who felt stigmatized just because they lived with disabilities. The study recommends that the government should mandate all teacher training institutions in the country to include a module on Inclusive Education as a core module that must be taken by all educators.
\end{abstract}

Keywords: Case study, disabilities, Focus Group, perception, wellness,

DOI: $10.7176 /$ RHSS/9-18-12

Publication date:September $30^{\text {th }} 2019$

\section{Orientation of the study}

According to the United Nations (UN) (1989), numerous policy decisions have been taken, globally, which have led to increasing inclusion of learners with special needs in mainstream schools influenced by international developments and agreements. Such policy decisions have recognized the right to education of learners living with disabilities as integral part of human rights. These policies are enshrined in international legal frameworks such as the UN Convention on the Rights of the Child (UNCRC) (UN, 1989) which promotes the right to education of all learners, including those living with disabilities. Also, The Jomtien World Declaration on Education for All (1990) commits that the curriculum, teaching and learning be child-centered to embrace diversity. Furthermore, the United Nations Educational Scientific and Cultural Organization (UNESCO) Salamanca Statement and Framework for Action (1994) advances the concept of inclusion for learners living with special educational needs including those with physical disabilities in the mainstream schools in their neighborhood. The Darker World Education Conference (2000) commits governments to ensure that an education system caters for the needs of all learners in an inclusive setup. Lastly, the UN Convention on the rights of Persons with Disabilities (UNCRPD) (2006) demands the provision of education for persons living with disabilities in an education system that is inclusive and responsive to the needs of all (Myers \& Bagree, 2011; Okeke \& Mazibuko, 2014; Nxumalo \& Lukhele, 2012).

The Eswatini Education and Training Sector Policy (EDSEC, 2011) is the main guiding legal document which promotes inclusion of learners living with special educational needs including those living with physical disabilities. Article 6.3 of this policy clearly expresses the aim to mainstream relevant and quality education for all different categories of learners including those living with physical disabilities in an inclusive school context. Consequently, there have been significant increases in the level of resources in mainstream schools for learners with special educational needs in terms of discrete teachers for learning support, resource, and language support as well as special needs assistants. All these efforts imply the recognition of the importance of education in the lives of all learners including those living with disabilities.

\section{Statement of the problem}

Education is a fundamental right for the development of individuals and societies at large and ensuring the right to education for persons with disabilities in particular; hence, it should not be overlooked. Literature reveals that inequality and discrimination in education are major concerns and need to be addressed (Jonas, 2005). As such, the international community has developed various legal frameworks to ensure that these learners attain the right to education equitably. In response to these policy documents, the government of Eswatini has developed various national policies and increased resource allocation to mainstream schools to support the education of learners living with physical disabilities in an inclusive environment. However, in spite of all these efforts, there seems to 
be a lack of effort in putting in place intervention strategies to enhance wellness of these learners in schools to justify inclusion in mainstream schools.

\section{Core objectives of the study}

The main objective of the study was to examine the views of teachers regarding the promotion of wellness of learners living with physical disabilities in primary schools in the Hhohho region.

\section{Review of related literature}

\subsection{Attitudes of teachers towards inclusion}

The extent literature provides mixed findings on the attitudes of teachers towards accommodating the needs of impaired students in regular facilities in both developed and developing worlds is alarming. In the context of Ghana, Kuyini and Mangope (2011) found that mentors are more inclined to focus on learners with mild and minor impairments than on those with severe disabilities. Agbenyega and Deku (2011) explored the Ghanaian mentors' practices in the regular educational settings based on a focus group of 21 teachers and documented that current models are prescriptive, inflexible, and do not value variety of learning styles of students. Kuyini and Abosi (2011) highlighted that most street learners in the capital city, Accra, exit enrolment because of highly inflexible teaching methods, which fail to accommodate their special learning needs. Such attitudes make it difficult for the learners to enjoy both psychological and intellectual wellness. In the researcher's opinion teachers must be well prepared and have a positive attitude towards learners living with disabilities. It is the positive attitude that creates positive classroom environments. This should be complemented by adaptive approaches such as explicit teaching, cooperative learning, and social skills instruction that could improve the learning outcomes of these learners.

\subsection{Large class sizes}

Instructing a high number of pupils often brings a myriad of challenges, and mentors are less likely to engage in adaptive practices to support children with SEN (Kuyini, 2013; Mukhopadhyay et al., 2012). This brings about some negativity in the way that learners living with physical disabilities are viewed. Some teachers view them as an extra burden in the classroom, something they are not prepared to handle. Furthermore, Kuyini (2013) posits that some teachers view large-size classes as reasons which make them unable to adjust learning materials or apply differentiated instruction and peer-assisted teaching models, and to interact effectively with special learners. In the end, this all has a telling effect on the academic wellness of the concerned learners. It is the researcher's opinion that in Eswatini a similar scenario exists where large classes are prevalent because of the Free Primary Education (FPE) initiative. Some teachers have been known to complain about the huge workloads and it is logical that giving individualized attention to learners living with disabilities may become difficult. It is the wellness of these learners which suffers most they are unable to get the deserved attention due to class sizes.

\subsection{Lack of training}

Thwala (2015) postulates that professional skills can only be achieved when one undergoes intense training. In her study about challenges encountered by teachers in managing inclusive classroom in Eswatini, she reveals that teachers acknowledge that they are not trained in preparation for inclusion in mainstream schools. They, however, believe that given an opportunity to practice basic inclusive classroom management skills, they can make it. Teachers complained about lack of knowledge of handling learners living with disability, including those living with physical disability. Thwala concludes that it is going to be a challenge for the kingdom of Eswatini to implement inclusive education if teachers are not trained and if the workshop provided are not adequate. This implies that the wellness of these learners is a huge challenge for the teachers because they lack the skills to promote it. Thwala (2015) and Rieser (2012) further reflect that teachers view themselves as lacking competency to teach in inclusive classrooms because they lack knowledge and skills to deal with learners living with disabilities, which becomes a challenge in meeting the challenge of the diverse needs of learners.

\subsection{Lack of concrete materials}

Studies reveal that learners living with disabilities, including those with physical disability, lack proper teaching and learning materials to accommodate their diverse individual needs, yet Thwala (2015) advances that learners think processes depend on concrete materials they manipulate. This stresses teachers because the EDSEC (2018) promises that government shall provide teaching and learning materials to cater for diversity. It may be concluded that, not until the government of Eswatini is able to provide learning resources such as magnifying glasses, tape recorders, hearing aids, overhead projectors and computers, inclusion shall remain rhetoric for learners living with physical disabilities (Rieser 2012; \& Armstrong et al., 2010). 


\subsection{Assessment}

Due to the problem of large classes as a consequence of the introduction of the FPE programme in primary schools in Eswatini, teachers often complain that it is a huge challenge for them to provide assessment activities. Thwala (2015) notes that classwork and tests are a way of providing feedback about learners' knowledge, skills and attitudes acquired during the teaching and learning process. However, due to the high teacher-pupil ratio, teachers are often compelled to adopt a blanket approach to assessment which negatively impact on the wellness of learners living with physical disability. This is injustice to these learners because inclusion requires that diverse assessment techniques be used to cater for all individuals' needs. As it is, these learners are in appropriately assessed, because assessment focuses more on what they cannot do rather than on their strength (Rieser, 2012).

\subsection{Theoretical framework}

The theory that underpinned this study was the Wellness Theory by Hettler (1980). This theory postulates that there are six dimensions of wellness, namely: academic, social, spiritual, physical, occupational, and emotional wellness. In this study, the researcher was interested in the academic, emotional, social, and physical wellness dimensions. The wellness served as lenses through which the researcher explored the experiences regarding the intervention strategies they use to enhance the wellness of learners living with disabilities.

There are several dimensions to defining wellness as illustrated in figure 1 below.

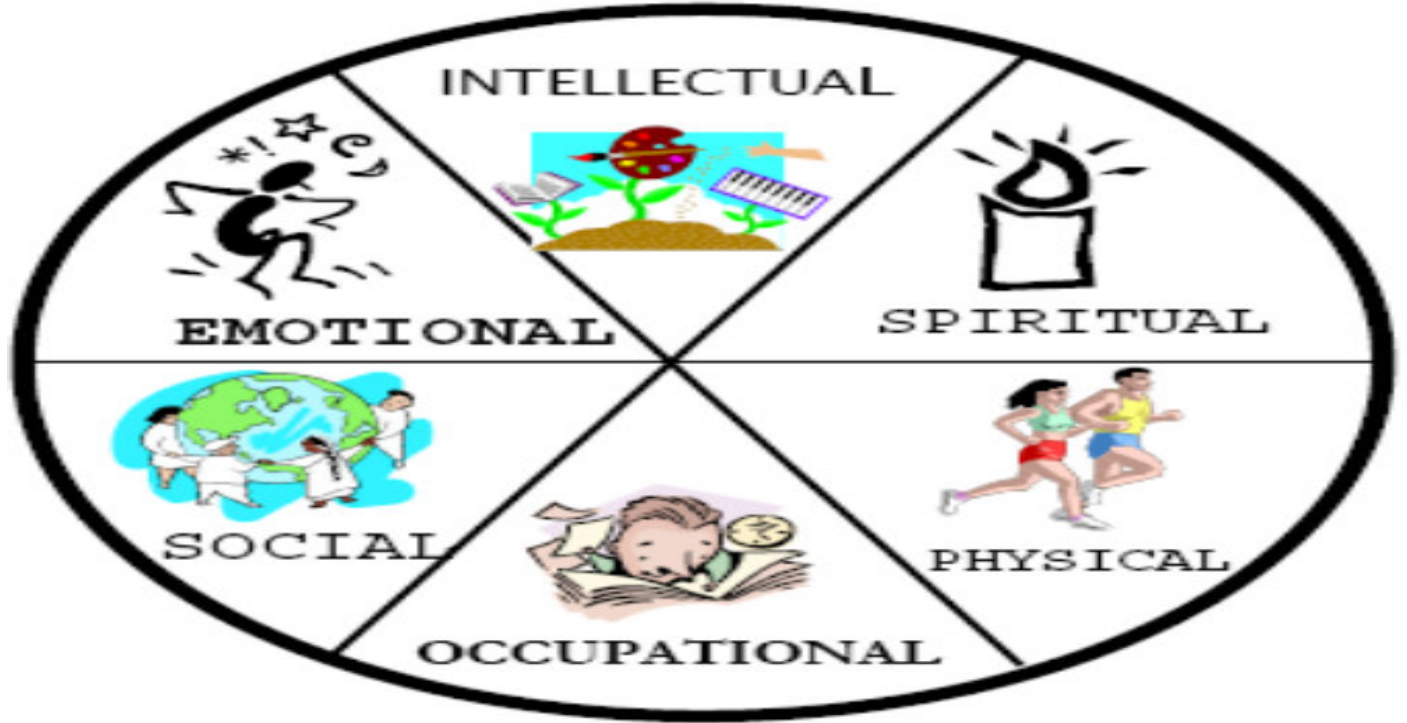

Figure 1: Dimensions of wellness

Adopted from: Helliwell (2005)

Academic wellness: encourages creativity and stimulates mental activities of the learners; uses the resources available to expand one's knowledge in improving skills. It focuses on the achievement, development, application, and extension of critical thinking, along with expanding one's potential for sharing knowledge with others beyond the classroom, and the larger community (Hettler, 1980).

Emotional wellness: concerns understanding and accepting one's own emotions and feelings and the emotions and feelings of others. Emotional wellness requires understanding and coping with problems that arise in everyday life.

Social wellness: is being comfortable, accepting others and sustaining healthy relationships (Anspaugh, Hamrick \& Rosato, 2004). Social wellness refers to the ability to perform social roles effectively, comfortably and without harming others.

Physical wellness: takes into consideration the barriers hindering the wellness of learners living with physical disabilities.

Spiritual Wellness: Renger et al. (2000) define spiritual wellness as the process of seeking meaning and purpose in existence. It includes the appreciation of the depth and expanse of life and the universe; questioning the meaning and purpose in life; as well as recognizing, accepting, and tolerating the complex nature of the world and accepting that the universe cannot be completely understood. Hettler (1980) adds that spiritual wellness is focused on harmony with self, and with others and the universe, and the search for a universal value system. This value system includes the formation of a worldview that gives unity, purpose, and goals to thoughts and actions. Hales (2005) defines spiritual wellness in terms of holistic dimensions, proposing four spiritual wellness dimensions: meaning in life, intrinsic values, transcendence, and spiritual community. The meaning in 
life dimension is described as an innate human need where purpose and life satisfaction provide hope. Intrinsic values are defined as the basis of human behaviour and the principles that people live by. Transcendence signifies a relationship with a higher force and the universe, recognition of the sacredness of life, and motivation by truth, beauty, and unity. The fourth dimension of spiritual community is defined as giving and sharing with others, shared values, myths and symbols, and the experience of community and mutual support through gathering, singing, praying, and chanting.

Occupational Wellness: Anspaugh et al. (2004) defines occupational wellness as the level of satisfaction and enrichment gained by one's work and the extent one's occupation allows for the expression of values. Furthermore, occupational wellness includes the contribution of one's unique skills and talents to the community in rewarding, meaningful ways through paid and unpaid work. Lastly, occupational wellness incorporates the balance between occupational and other commitments. Leafgren (1990) stated that occupational wellness refers to one's attitude about work and the amount of personal satisfaction and enrichment gained from work.

\section{Research methodology}

\subsection{Nature of the study}

To satisfy the objectives of the study a qualitative approach to research was followed. For this research, the interpretivist research philosophy was used because the study gave an opportunity to use the social world as the basis for construction knowledge. It was critical to create knowledge from the lived experiences of those affected by the problem this included engaging the teachers and learners in real inclusive school set ups.

\subsection{Sampling and Sample Size}

The researchers intentionally selected two administrators, three teachers and 20 learners in the same mainstream school who were willing to participate in the study. It was assumed that the teachers were knowledgeable about issues concerning the promotion of wellness of learners living with disabilities because they educate them on a daily basis. Their academic credentials, age and experience in dealing with such learners was considered appropriate for each teacher. The learners selected to participate were selected because they had specific physical disabilities; were in the upper grades and between the ages 11 and 15. The total sample size of the participants for this study was 25 .

\subsection{Data collection}

The researcher used a semi-structured interview guide and focus group discussion guide as primary tools for data collection. To allow collection of detailed data, face to face interviews were also used.

\section{Findings}

\section{Theme 1: Poor Infrastructure}

The challenge all participants seemed to share was that of poor infrastructure. Data collected from the face-toface interviews with the three teachers and two administrators indicate that all participants were of the view that the school had very poor infrastructure, this was cited as one of the major barriers learners living with physical disabilities faced during their time in the school. In this regard, the teachers and administrators gave various responses in support of this view which were analyzed and presented in four sub-themes namely: inaccessible facilities, inappropriate furniture, kitchen too far away, and improper sports facilities.

Inaccessible facilities: Pertaining the inaccessible facilities, four of the five teacher participants submitted that the facilities in and around the school were highly inaccessible for learners living with physical disabilities which negatively affected their wellness. In support of this view, one of the participants reported:

In my view, the most dominant barriers that learners living with physical disabilities face in this school are the issue of highly inaccessible facilities. For instance, the design of some of the classrooms is such that make it hard for learners who are wheel chair bound to access because there are no ramps. Also, there are stair cases, even though minimal, which render the classroom inaccessible thus limiting their freedom of participating in educational experiences. I wish that the school can work on removing these obvious barriers, to enable learners to move around freely and to improve accessibility of the classrooms (Teacher \#2: 43 year-old).

It is evident from the statement given by teacher \#2 that the school facilities are barriers for learners living with physical disabilities which hinder their wellness. The focus group with learners living with physical disabilities confirmed this concern as 15 out of the 20 participants (75\%) identified the school facilities as inaccessible, as one of the participants noted:

I struggle a lot to get to my classroom every day because classroom is inaccessible for my wheel chair. Consequently, I rely on my friends and teachers to help me move around. Sometimes it delays me from classes and I miss a lot because I sometimes arrived when lessons have already started when help is delayed. I wish there was an easier way to get to my classroom and also other 
places around the school (Learner \# 13, 17 year-olds, Grade 7 girl).

\section{Theme 2: Lack of relevant skills}

The lack of relevant skills was also revealed as a serious challenge by the participants. A majority of the participants revealed that they lacked the relevant skills to meet the needs of learners with physical disabilities. Two sub-themes emerged from the analysis of data that support this view namely: inadequate training for teacher, and lack of competency to work with learners with physical disabilities. The majority of the teacher participants who were interviewed revealed that the teachers at the school did not have adequate training to enable them to fully assist learners living with physical disabilities. One participant stated:

The concept of inclusive education has been officially introduced in the school's system for a number of years now. The reality however is that the majority of teachers have not been comprehensively trained on how to effectively assist a learner who, for instance, is wheel chairbound. Only a few of the new teachers covered the concepts in their pre-teacher training. Not all teachers have had the privilege of in-service training on inclusive education. In my opinion this contributes to the poor service that learners living with physical disabilities end up facing (Head teacher \#1, 48 years old).

This view was also supported by another teacher who had this to say:

Teaching learners of various abilities is very tough, it needs proper training on how to positively deal with all the needs and challenges brought about by the inclusion of learners with physical disabilities in a class. I had no idea that the class layout, for instance, is critical when you have learners who are wheelchair bound or other impairments. Training of teachers on how to help learners effectively is really critical. Unfortunately, the in-service training workshop provided by MoET are inadequate as they are conducted for a very short duration old time (Teacher \#3, 46 years old).

Based on these responses, it is clear that not all teachers have received adequate training to enable them to effectively assist learners living with physical disabilities. It is implied that teachers should continue receiving in-service training in Inclusive Education to increase their competence and effectiveness in teaching these learners.

\section{Theme 3: Unfavourable environment to enhance wellness}

The lack of favorable environment to enhance wellness was another challenge that emerged during the analysis of responses of the participants. This includes stigmatization by peers. Fifteen out of the 20 learners living with physical disabilities revealed that they felt stigmatized in the school because of their disabilities. One learner stated that:

The very first few days I came to the school were difficult as some of the learners did not understand why I was different from them since I could not walk or run as they do. They looked at me strangely and some even laughed at me. It was a painful experience for me but now I have friends and most accept me. The teachers are good to me also as they encourage me to report other learners who mock me (Learner \# 1, 14 year-old, Grade 6 girl).

One of the teachers who was interviewed confirmed this, by stating:

We try very hard to teach learners to accept and socialize with the learners living with disabilities, however occasionally, some misbehave and tease or say bad words simply because the other learner is different. As a teacher if this happens in my class, I use it as an example to the rest of the class that no learner has the right to mock others based on their disability and this is part of classroom management (Teacher \# 2, 43 year-old).

It is evident from the finding above that learners living with physical disabilities are stigmatized by their normal peers, despite the effort made by teachers to put an end to such behavior. The majority of the participant, 12 out of the 20 participants stated that they experienced some form of bullying related to food. The majority of incidences were reported to be happening during break time where learners receive food from the kitchen. One participant confirmed this by stating:

Some of the older boys harass me over the food provided in the school and they sometimes take it by force from me. When that happens, I usually go hungry for the whole day. I don't like going to the kitchen because they take my food because they know I can't fight them. I sometimes feel like staying at home because I do not like what these boys are doing to me (Learner \# 2, 12 yearold, Grade 5 boy).

One of the administrators confirmed participant \# 2's assertion, that learners living with physical disability are bullied by their peers over food. The administrator concurred:

Occasionally, we deal with cases of bullying of learners living with physical disabilities by their normal peers, which usually happen during break time or even outside the school. We strive to ensure that the perpetrators are positively discipline to show them proper conduct as reflected in the school regulators (Head teacher \#1 48 year old). 
Theme 4: Intervention strategies used by the school to enhance wellness of learners living with physical disabilities.

All the five teacher participants revealed that they encourage other learners to help those living with physical disabilities to move around the school to cope with the poor infrastructure. One participant stated:

We encourage their peers to help them to move around the school especially when going to the school soup kitchen, toilets or even to the staffroom. The head teacher encourages this good behaviour during the school assembly time. It pleases me to see the other children meeting and assisting learners living with physical disabilities in the morning and after school when the taxi drops and picks them up. We take advantage of the willing learners by encouraging them to assist their friends especially those in wheel chairs (Teacher \# 2, 43 year-old).

All the learners who participated in the study concurred that they rely on their friends' help to move around the school. One participant reported that:

I always move where it will be conducive for me because some of the places have not been modified. I do not trouble myself with those which are unreachable even though I wish to access them and the classmates also supports me (Learner \#18, 17 year old, Grade 7 boy).

Adaptation of infrastructure: A majority of the teacher participants concurred that they rely on the partnership they have developed with some non-government organizations, the Department of Special Needs Education under the MoET, and the Parent Teacher Association (PTA) to address the infrastructural barriers experienced by learners living with physical disabilities. One participant asserted saying:

We mostly rely on the parents of learners living with physical disabilities, the officials from the Department of Special Needs Education from the MoET, and non-governmental organizations to support the school financially in addressing some of the infrastructural barriers. Although the school has just formed the Parent Teacher Association, we hope it will help a lot in the future in meeting the needs of learners living with disabilities. The PTA helps in raising some money for the school to meet the needs of these learners. The Department of Special Needs help in organising some sponsors to help in adapting the school environment. Even though the response from such donors is low but we have some ramps in the school corridors through such efforts (Teacher \# 2, 43 year-old)

\section{Conclusion and Recommendations}

\subsection{Conclusion}

From the findings, a number of conclusions can be reached. It was conclusive that teachers lack the competence and the relevant skills needed to effectively teach these learners. There is lack of social wellness among learners living with physical disabilities. This is because learners experience deep social problems including stigmatization and bullying. The training of teachers as the key intervention strategy which can improve the wellness of learners living with physical disabilities in the long term.

\subsection{Recommendations}

Following the findings, the following recommendations are suggested to meet the needs of all learners:

- the school must implement a strong parental involvement programme which will encourage teachers and parents to work together to meet the needs of leaners living physical with disabilities;

- there is need for establishing a fully-fledged guidance and counselling office to offer constant services to learners with various issues; and

- the government should also mandate all teacher training institutions in the country to include a module on Inclusive Education as a core module that must be taken by all educators.

\section{References}

Anspaugh, D., Hamrick, M., \& Rosato, F. (2004). Wellness and fitness for life (6th ed.). Boston, MA: McGraw Hill.

Armstrong, A. C., Armstrong, D. \& Spandagou, I. (2010). Inclusive Education: International Policy and Practice. London: Sage.

Babbie, E. (2010). The practice of social research. London: Wadsworth Cengage Learning.

Babbie, E., \& Mouton, J. (2010). The practice of social research. Cape Town: Oxford University Press.

Creswell, J. W. (2012). Educational research: planning, conducting, and evaluating quantitative and qualitative research / John W. Creswell. - 4th ed.

Creswell, J.W. (2014). Research Design: Quantitative, Qualitative and Mixed Methods Approach (4th ed.), Los Angeles: Sage.

Denzin, N. K. (2010). Moments, mixed methods, and paradigm dialogs. Qualitative Inquiry, 16(6):419-427.

Gall, M. D; Gall, J.P., \& Borg, W.R (2007). Educational Research: An introduction, 8th edition, USA: Pearson 
education Inc.

Gay, L. R., Geoffry, E.M., \& Peter, A. (2009).Educational research: Competencies for analysis and Application. London: Pearson.

Hales, D. (2005).An Invitation to Health, (11th ed) Belmont, CA: Thomson \& Wadsworth.

Helliwell, J. F. (2005). Well-being, Social Capital and Public Policy: Massachusetts Avenue: Cambridge.

Hettler, B. (1980). Wellness promotion on university campus. Family and community health. Journal of Health Promotion and Maintenance, 3(1):77-95.

Jonas, S. (2005). The wellness process for healthy living: A mental tool for facilitating progress through the stages of change. AMAA Journal, Health Care Industry, Winter, 2005.

Krueger, R. A. (2006). Is it a focus group? Tips on how to tell. J Wound Ostomy Continence Nurs33(4): 363-6.

Kuyini, A. A. B., \&Mangope, B. (2011). Student teachers' attitudes and concerns about inclusive education in Ghana and Botswana. International Journal of Whole Schooling, 7(1), 1-18.

Kuyini, A. A. R. (2013). Teachers' pedagogical competencies in including children with learning difficulties in primary schools in Ghana (Unpublished $\mathrm{PhD}$ thesis). University of Brunei Darussalam, Bandar Seri Begawan.

Kuyini, A. A. R., \&Abosi, O. (2011). The 2nd Generation Street Children (SGSC) in Accra: Developing teaching strategies to enhance positive learning outcomes in schools. World Journal of Education, 1(2), 161-171.

Leafgren, F. (1990). Being a man can be hazardous to your health: Life-styles issues. In D. Moore \& F. Leafgren (Eds.), Problem solving strategies and interventions for men in conflict (265-311).

Leedy, P. D., \&Ormrod, J. E. (2012). Practical Research: Planning and Design (10th.ed.). New Jersey: Pearson Merrill Prentice Hall.

McMillan, J. H. \& Schumacher, S. (2010). Research in education: Evidence based inquiry,( 7th ed.). Boston: Pearson.

Mukhopadhyay et al. (2012),

Myers, J., \&Bagree, S. (2011). Policy Paper Making Inclusive Education a Reality. West Sussex: Grosvenor Hall.

Nxumalo, C.P., \&Lukhele, B.S., (2012). Inclusive Education Responses, Challenges and Prospects for Eswatini. Mbabane: MoET.

Okeke, C. I. O., \&Mazibuko (2014). Mainstreaming and Inclusion: Challenges faced by Swazi Parents of Schools. University of Fort Hare: East London Campus.

Rieser, R. (2012). Implementing Inclusive Education: A Commonwealth Guide on the Rights of Persons with Disabilities (2nd Edition): London, Charlesworth.

Thwala, S. (2015). Challenges Encountered by Teachers in Managing Inclusive Classrooms in Eswatini. Mediterranean Journal of Social Sciences, 1 6, 1 January 2015.

UN (1989).Convention on the Rights of Persons with Disabilities. www.un.org

UNESCO (1994).The Salamanca Statement and Framework for Action on Special Needs Education. Adopted by the World Conference on Special Needs Education: Access and Quality. Salamanca, Spain, 7-10 June.

UN Convention on the rights of Persons with Disabilities (UNCRPD) (2006)

Webb, C., \&Kevern J. (2008). Focus groups as a research method: A critique of some aspects of their use in nursing research. Journal of Advanced Nursing, 33. 